\title{
Estratégia\&Negócios
}

ISSN 1984-3372

http://www.portaldeperiodicos.unisul.br/index.php/EeN/

\section{DETERMINANTES DO NÍVEL DOS ESTOQUES PÚBLICOS: MENSURAÇÃO NAS CAPITAIS DOS ESTADOS DA REGIÃO SUL DO BRASIL}

\section{DETERMINING THE LEVEL OF PUBLIC STOCKS: MEASUREMENT IN THE CAPITAL OF THE MEMBER OF THE SOUTHERN REGION OF BRAZIL}

\section{Paulo Sérgio Almeida dos Santos}

Mestrando do Programa de Pós-Graduação em Ciências Contábeis da Universidade Regional de Blumenau - FURB Bolsista da Fundação de Apoio a Pesquisa Cientifica do Estado de Santa Catarina - FAPESC

E-mail: paulosergio@al.furb.br

\section{Odir Luiz Fank}

Mestrando do Programa de Pós-Graduação em Ciências Contábeis da Universidade Regional de Blumenau - FURB E-mail: odirfank@hotmail.com

\section{Patrícia Siqueira Varela}

Professora do Programa de Pós-Graduação em Ciências Contábeis da Universidade Regional de Blumenau - FURB Doutora em Controladoria e Contabilidade pela Faculdade de Economia, Administração e Contabilidade da Universidade de São Paulo - FEA/USP.

E-mail: pvarela@furb.br

Recebido em 23/03/2011. Aprovado em 03/04/2012. Disponibilizado em 01/10/2012. Avaliado pelo Sistema double blind review

R. eletr. estrat. neg., Florianópolis, v.5, n.2, p.28-55, mai./ago. 2012 http://portaldeperiodicos.unisul.br/index.php/EeN/index
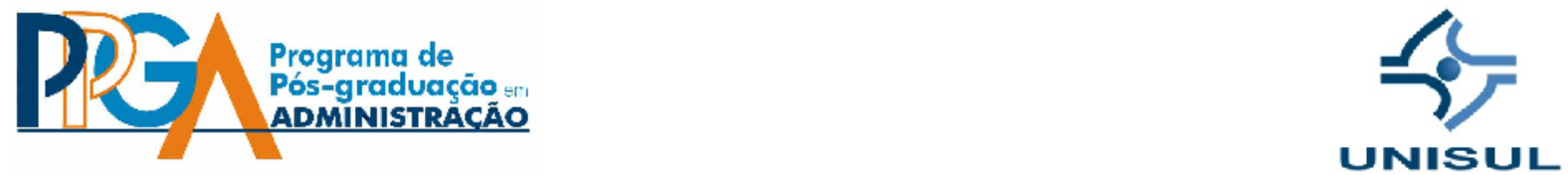

CCopyright 2008 UNISUL-PPGA/Estratégia e Negócios. Todos os direitos reservados. Permitida citação parcial, desde que identificada a fonte. Proibida a reprodução total. Em caso de dúvidas, consulte o editor: ademar.unisul@gmail.com; (48) 3229-1932. 
DETERMINANTES DO NÍVEL DOS ESTOQUES PÚBLICOS: MENSURAÇÃO NAS CAPITAIS DOS ESTADOS DA REGIÃO SUL DO BRASIL

Paulo Sérgio Almeida dos Santos - Odir Luiz Fank - Patrícia Siqueira Varela

\section{RESUMO}

As entidades tanto privadas como públicas têm como meta manter seus estoques equilibrados, objetivando a economicidade de recursos, pois os estoques necessitam de investimentos muitas vezes altos, e esses investimentos precisam produzir retorno financeiro para as entidades privadas e para o setor público os investimentos em estoques precisam suprir as necessidades vigentes. Nesse contexto, o estudo teve como objetivo avaliar os níveis de estoques das prefeituras das capitais dos estados da Região Sul do Brasil, bem como os seus determinantes e evolução ao longo do tempo. Para atingir o objetivo geral proposto, a pesquisa pode ser classificada quanto aos seus objetivos como descritiva, no que tange ao procedimento documental e quanto à abordagem do problema, quantitativo. A amostra da pesquisa compreende as capitais dos estados da Região Sul do Brasil. Para o cálculo dos dados, foram aplicadas as fórmulas matemáticas preconizadas na Instrução Normativa n 205/88. Os resultados sinalizam que ocorreram problemas referentes à falta de estoques nos almoxarifados das prefeituras. Tal problema possivelmente pode ser gerado em torno das saídas de mercadorias, tendo em vista questões de fins organizacionais das prefeituras. Portanto, as saídas de suprimentos aos diversos setores da administração municipal são registradas antecipadamente a entradas de suprimentos no almoxarifado, nos quais os materiais já estão devidamente alocados. Contudo, a visão de planejamento e estratégia na administração dos estoques públicos faz-se necessário, já que grandes são os custos em tornos dos estoques, para maximizar o valor do serviço público, afetando desse modo o oferecimento dos bens e serviços à população da região.

Palavras-chave: Estoques públicos. Compras públicas. Controle de estoques. Prefeituras. Região Sul do Brasil. 


\section{INTRODUÇÃO}

Devido à relevância que apresenta, tanto nas organizações públicas quanto nas privadas, os estoques devem ser alvo de atenção especial, pois uma quantidade considerável de itens em estoque pode gerar custos adicionais, tais como os relacionados à armazenagem, ao manuseio e ao controle. Em relação aos estoques, ludícibus, Martins e Gelbeck (2003, p. 115) definem estoques como sendo "bens tangíveis ou intangíveis adquiridos ou produzidos pela empresa com objetivo de venda ou utilização própria no curso normal de suas atividades".

Os estoques devem receber atenção especial no seu controle para poder proporcionar o retorno esperado. Mota e Cancio (2004) relatam que o tema controle de estoques é bastante discutido na administração pública com o intuito de identificar melhores práticas a serem aplicadas aos estoques, buscando a redução e a adequação dos seus níveis e, consequentemente a melhor aplicação dos recursos públicos.

Os problemas mais comuns relacionados aos estoques são os excessos ou falta de estoques, o que, segundo Costa, Gonçalves e Giacobo (2005) dificultam a definição das políticas de estoques, criando obstáculos quanto à determinação do nível de estoque adequado, à quantidade a ser requisitada e ao momento da requisição. Ainda, conforme os autores, outro problema, que afeta os resultados dos serviços públicos é o desvio de materiais ou bens pertencentes ao patrimônio público, isto é, a corrupção que há por parte dos agentes públicos que se apropriam indevidamente de ativos ou fazem uso dos mesmos para os seus interesses particulares. Os autores mencionam ainda que os desvios serão maiores ou menores em virtude das características da gestão dos estoques. Diante do supracitado, formula-se a seguinte questão de pesquisa: qual o comportamento dos níveis de estoques das prefeituras das capitais dos estados da região sul do Brasil, bem como os seus determinantes e evolução ao longo do tempo? 


\section{DETERMINANTES DO NÍVEL DOS ESTOQUES PÚBLICOS: MENSURAÇÃO NAS CAPITAIS DOS ESTADOS DA REGIÃO SUL DO BRASIL}

Paulo Sérgio Almeida dos Santos - Odir Luiz Fank - Patrícia Siqueira Varela

Diante desse questionamento, a presente pesquisa tem como objetivo identificar os níveis de estoques das prefeituras das capitais dos estados da região sul do Brasil, bem como os seus determinantes e evolução ao longo do tempo. A pesquisa foi realizada com base nas equações definidas pela Instrução Normativa no 205 de 08 de abril de 1988, da ex-Secretaria de Administração da Presidência da República SEDAP/PR, que tinha como finalidade racionalizar, com a minimização de custos, o uso de material no âmbito da Administração Pública Federal.

A referida Instrução Normativa indica a utilização de fórmulas matemáticas para definição de níveis de estoques compatíveis com a política traçada pelo órgão ou entidade. Tais fórmulas foram aplicadas aos números contábeis extraídos da base de dados FINBRA - Finanças do Brasil, no site da Secretaria do Tesouro Nacional, sobre as prefeituras de Curitiba, Florianópolis e Porto Alegre, referentes aos anos de 2002 a 2008. Mota e Cancio (2004) asseguram que a norma além de orientar a utilização das regras matemáticas para gestão dos estoques, também trata de conceitos, procedimentos e responsabilidades para um controle de estoque efetivo. A análise dos dados teve como referencial teórico livros, artigos e dissertações, ambos nacionais, que abordam o assunto compras e gestão de estoques, inclusive com aspectos inerentes ao setor público.

Entende-se que o estudo é relevante na medida em que gera conhecimento sobre gestão de estoques das entidades públicas. Espera-se que as ideias apresentadas e discutidas possam contribuir para a minimização dos problemas relativos aos estoques, além de servir de subsídio para outras pesquisas relacionadas ao setor público brasileiro, as quais ainda são mínimas quanto à área temática finanças públicas. 


\section{REFERENCIAL TEÓRICO}

\subsection{COMPRAS NO SETOR PÚBLICO}

A atividade de compras, tradicionalmente, tem sido vista como uma simples atividade administrativa e burocrática, com objetivo de operacionalizar um pedido de suprimento solicitado por algum setor da organização. Freitas, Medeiros e Melo (2008) mencionam que esse quadro está se alterando, pois as organizações perceberam a relevância dessa função logística. Para os autores, a atividade de compra tem potencial de reduzir gastos monetários, pois com a adequada aquisição de materiais e a otimização do desempenho de outras atividades, tais como produção e gestão de estoques, a empresa pode obter economia no investimento nos estoques.

Para Saldanha (2006, p.138) o conceito de compras no setor público envolve:

[...] todo o processo de localização de fornecedores, fonte de suprimento, consulta, escolha e aquisição de materiais por meio de licitações que envolvem quantidade, qualidade, preço (condições de pagamento, desconto), prazo de entrega, transporte, bem como o acompanhamento de processo perante o fornecedor escolhido e o recebimento do material para inspecionar e garantir o fornecimento dentro das especificações solicitadas.

Conforme o autor, a atividade de compras requer uma atenção especial, pois a adequação na sua realização pode oportunizar vantagens financeiras, aumentando assim a eficiência e a eficácia das ações estatais. O autor ressalta que se as compras não forem executadas com responsabilidade, podem resultar em consequências desastrosas para a organização.

Segundo Dias (1995), os objetivos das atividades de compras são: (1) manter fluxo contínuo de suprimentos, (2) coordenar esse fluxo buscando o mínimo de investimento, sem afetar a operacionalidade, (3) comprar materiais a preços mais baixos, dentro dos padrões de quantidade e qualidade definidos, (4) procurar as 
DETERMINANTES DO NÍVEL DOS ESTOQUES PÚBLICOS: MENSURAÇÃO NAS CAPITAIS DOS ESTADOS DA REGIÃO SUL DO BRASIL

Paulo Sérgio Almeida dos Santos - Odir Luiz Fank - Patrícia Siqueira Varela

melhores condições (desconto, preço, prazo de pagamento, forma e prazo de entrega e qualidade) para a organização.

No setor público, o processo de compra segue procedimentos e formalidades específicas que buscam garantir a compra pelo melhor preço. O processo de compras precisa apresentar a transparência e a ética na utilização dos recursos públicos, o que vem sendo requerido da administração pública pela sociedade, com exigências quanto à responsabilidade com a realização dos gastos públicos (DIAS, 1995).

Conforme Freitas, Medeiros e Melo (2008), da necessidade de fixar regras para os processos licitatórios governamentais e do movimento por maior ética no setor público, surgiu a Lei no 8.666 de 21 de junho de 1993, que resumiu e sistematizou uma série de normas gerais sobre licitações e contratos administrativos realizados no âmbito do poder público federal, estadual e municipal. Além dos vários aspectos introduzidos pela lei, destacam-se também o sistema de registro de preços (SRP) e o pregão, regulamentados pelo Decreto Federal no 3.931 de 19 de setembro de 2001 e pela Lei no 10.520 de 17 de julho de 2002, respectivamente, e que representam alternativas para a redução dos gastos totais com estoques. Sobre o sistema de registro de preços, Fernandes (2003, p. 1) menciona que o:

SRP é um forte aliado dos princípios da eficiência e da economicidade, por ser um procedimento que resulta em vantagens à Administração, como a desburocratização das aquisições, redução do volume de estoque, redução da quantidade de licitações, propicia e facilita um maior número de ofertantes, inclusive a participação das pequenas e médias empresas, enxuga os gastos do erário, entre outras vantagens apresentadas ao longo da pesquisa.

O sistema de registro de preços estabeleceu a possibilidade de entrega parcelada dos bens ou serviços licitados, durante um período máximo de um ano, e o compartilhamento dos preços registrados em processos licitatórios realizados pelos demais órgãos estaduais, por meio de adesão às Atas de Registro de Preços. (FREITAS; MEDEIROS; MELO, 2008). 


\section{DETERMINANTES DO NÍVEL DOS ESTOQUES PÚBLICOS: MENSURAÇÃO NAS CAPITAIS DOS ESTADOS DA REGIÃO SUL DO BRASIL}

Paulo Sérgio Almeida dos Santos - Odir Luiz Fank - Patrícia Siqueira Varela

Em relação ao pregão, o mesmo se destaca por ser um conjunto de esforços do poder público na busca de flexibilizar, desburocratizar o procedimento licitatório, tornando-o mais simples e acessível. Tomem, Metzne e Braun (2007) relatam que o pregão é condicionado aos princípios básicos da legalidade, impessoalidade, moralidade, igualdade, publicidade, eficiência. Os autores ressaltam que as normas disciplinares sempre serão interpretadas em favor da ampliação da disputa entre os interessados, desde que contemplem os interesses da administração pública.

Conforme mencionado na literatura, as compras no setor público seguem o processo licitatório, que objetiva maior transparência e ética no processo de compras. Esse processo licitatório pode se tornar muito burocrático, fato que fez surgir outras formas de compras, como o pregão.

\subsection{CONTROLE DE ESTOQUES NO SETOR PÚBLICO E EVIDÊNCIAS EMPÍRICAS}

Para uma adequada administração do processo produtivo de uma entidade, o planejamento e o controle de estoques são de fundamental importância, tendo que se preocupar com os problemas quantitativos e financeiros dos materiais, independentemente de serem matérias-primas, materiais auxiliares, materiais em processo ou produtos acabados (POZO, 2008).

Ainda conforme Pozo, o setor de controle de estoques é responsável pelo controle das disponibilidades e das necessidades totais do processo produtivo, desde as matérias-primas até os produtos acabados, e sendo responsável pelas quantidades físicas em estoque, buscando evitar a paralisação do processo fabril nas indústrias, ou a falta de mercadorias nas empresas que revendem mercadorias ou nos órgãos públicos. 


\section{DETERMINANTES DO NÍVEL DOS ESTOQUES PÚBLICOS: MENSURAÇÃO NAS CAPITAIS DOS ESTADOS DA REGIÃO SUL DO BRASIL}

Paulo Sérgio Almeida dos Santos - Odir Luiz Fank - Patrícia Siqueira Varela

Para Saldanha (2006), a quantidade excessiva de estoques ou a sua falta traz reflexos negativos para o setor governamental, que carece de controles mais eficientes. Ainda conforme o autor,

[...] o controle de estoque consiste na identificação dos diversos tipos de materiais a serem armazenados, transitoriamente, levando-se em conta, no dimensionamento de cada um deles, as entradas, as saídas e os saldos ocorridos em determinados períodos de tempo, bem como o giro de estoque previsto, além dos aspectos envolvidos para saber qual o momento de solicitar uma nova compra. (SALDANHA, 2006, p. 146)

O autor ressalta que $\mathrm{o}$ adequado controle de estoques se torna fundamental, pois, além dos produtos entrarem adequadamente armazenados no depósito de materiais, é preciso prever situações para que não haja excessos, faltas, nem deterioração dos materiais estocados.

Para Dias (1995), alguns passos precisam ser seguidos para realizar um adequado controle de estoques, entre eles: (1) determinar que tipos de materiais que serão estocados, (2) determinar a quantidade de cada tipo de material, (3) determinar o tempo de renovação dos estoques, (4) determinar responsáveis para executar a compra, receber as mercadorias, armazenar e controlar os estoques, (5) executar controle sobre os estoques e inventários periódicos, e (6) identificar a importância dos materiais a serem estocados.

A determinação dos tipos de materiais e a sua quantidade são fatores importantes para um bom controle de estoques. Manter estoques em níveis adequados é um dos grandes desafios que, tanto órgãos públicos como privados enfrentam diariamente. Para Santos, Teixeira e Carvalho (2009), uma das deficiências do setor público é a ausência de um sistema integrado, como os chamados ERPs (Enterprise Resources Planning), pois, eles trazem uma qualidade melhor ao controle interno. Moresi (2000) relata que os sistemas integrados auxiliam na redução de custos, na melhoria de produtividade e eficiência e, facilita os registros de entradas e 
DETERMINANTES DO NÍVEL DOS ESTOQUES PÚBLICOS: MENSURAÇÃO NAS CAPITAIS DOS ESTADOS DA REGIÃO SUL DO BRASIL

Paulo Sérgio Almeida dos Santos - Odir Luiz Fank - Patrícia Siqueira Varela

saídas dos almoxarifados públicos, prevenindo a entidade quanto ao excesso ou falta de materiais.

Para o controle dos estoques são utilizadas algumas técnicas. Para Braga (1995), Assaf Neto e Silva (2007), Quelhas et al., (2008), Ching (1999), as técnicas de administração mais utilizadas são: sistema da curva $A B C$, lote econômico de compras, ponto de pedido, estoque de segurança e o just in time.

Braga (1995) acredita que a curva $A B C$ faz uma hierarquização dos estoques da empresa, separando-os pelo grau de importância que tem para o faturamento. Conforme o autor, com essa hierarquização dos estoques, os administradores podem voltar suas atenções para os itens que tem maior participação no faturamento, mantendo um controle não tão rigoroso sobre os demais itens. Conforme Braga (1995) e Assaf Neto e Silva (2007), o método da curva ABC classifica os produtos nos grupos A, B e C. Os itens que compreendem o grupo A representam um pequeno número de itens, mas com alta participação no valor total dos estoques e no total do faturamento. Os itens do grupo C representam grande número de itens, porém com reduzida expressão no valor total dos estoques e pequena participação no faturamento da empresa. Os itens do grupo B são aqueles situados entre as duas categorias, sendo considerados produtos intermediários tanto nos valores quanto na significância no faturamento. Com a classificação dos itens dos estoques, os gestores têm a vantagem de poder dar maior atenção aos itens mais representativos.

O lote econômico de compra, conforme Assaf Neto e Silva (2007) é um modelo que procura determinar a quantidade que deve haver no estoque e o período que serão feitos novos pedidos, sempre analisando os custos de pedido e de estocagem para que os custos totais sejam os menores possíveis. Será por meio do custo de pedido e de estocagem que o lote econômico de compra refletirá a melhor quantidade de produto a ser pedido. Braga (1995) menciona que o lote econômico de compra é um método que busca dar uma resposta ótima com respeito ao volume de 
DETERMINANTES DO NÍVEL DOS ESTOQUES PÚBLICOS: MENSURAÇÃO NAS CAPITAIS DOS ESTADOS DA REGIÃO SUL DO BRASIL

Paulo Sérgio Almeida dos Santos - Odir Luiz Fank - Patrícia Siqueira Varela

unidades que deverão ser adquiridas ou processadas, obtendo o ponto em que o custo da gestão de estoque seja mínimo.

Em relação ao ponto de pedido, Braga (1995) menciona que os pedidos de compras de materiais ou de mercadorias devem ser feitos quando as quantidades estocadas chegarem a níveis que cubram apenas os estoques de segurança fixados e os consumos ou vendas previstas para o período que corresponde aos prazos de entrega dos fornecedores. Conforme o autor, a quantidade determinada no ponto de pedido tem que ser suficiente para atender à demanda durante o período em que o item é reposto, evitando assim falta do produto. Quelhas et al. (2008), ilustra o modelo de ponto de pedido por meio do exemplo do abastecimento de combustível em um automóvel. O proprietário abastece o veículo somente quando o nível de combustível no tanque está na reserva, ou em qualquer outro nível que ele considere como limite de alerta para se procurar um posto e encher o tanque. Dessa forma, o modelo ponto de pedido se caracteriza por intervalos variáveis de pedido, em função do quantitativo consumido ao longo do tempo.

O estoque de segurança, conforme Assaf Neto e Silva (2007) é um método que as empresas utilizam para evitar eventual falta de estoque, evitando perda de vendas pelo não atendimento do cliente. Para os autores, no método é analisada a demanda de certo produto e sobre essa demanda é colocado uma margem de segurança de produtos que possam suprir uma eventual variação da demanda. Os autores mencionam que quanto maior a instabilidade na demanda de determinado produto, maior deve ser o investimento em estoque de segurança. O gestor da empresa deve analisar se esse investimento no estoque de segurança trará rentabilidade.

Quanto ao just in time, Ching (1999) menciona que visa a atender a demanda de forma instantânea, com qualidade e sem a necessidade de estoques. Para Assaf Neto e Silva (2007), o just in time é uma filosofia de gestão empresarial criada no Japão, que se baseia na eliminação total dos estoques e produção puxada pela 
DETERMINANTES DO NÍVEL DOS ESTOQUES PÚBLICOS: MENSURAÇÃO NAS CAPITAIS DOS ESTADOS DA REGIÃO SUL DO BRASIL

Paulo Sérgio Almeida dos Santos - Odir Luiz Fank - Patrícia Siqueira Varela

demanda. Segundo os autores, com o just in time a empresa começa a produção somente quando o produto estiver demandado pelo cliente.

Conforme Ching (1999), a implementação do just in time requer alguns princípios, entre os quais: qualidade, velocidade, confiabilidade, flexibilidade e compromisso entre o fornecedor e empresa cliente. A qualidade deve ser constante, pois os desvios poderão comprometer o processo produtivo. A velocidade é fundamental para o atendimento contínuo das necessidades dos clientes. A confiabilidade torna-se pré-requisito para a manutenção constante das atividades produtivas. A flexibilidade representa capacidade de produzir aquilo que o cliente quer, desde pequenos lotes até pedidos maiores, reduzindo o tempo de resposta. 0 comprometimento entre o fornecedor e a empresa cliente torna-se essencial para que a filosofia do just in time funcione (CHING, 1999).

Segundo Assaf Neto e Silva (2007), para a empresa atingir o objetivo do just in time, que é a eliminação dos estoques, ela deve alterar o processo produtivo, buscando reduzir ao máximo o número de defeitos, reduzir o tempo que não agrega valor, reduzir o volume de matéria-prima comprada do fornecedor por lote, a movimentação dos estoques e a complexidade do processo de produção.

Nesse contexto de avaliação dos níveis de estoques, gestão de estoques, técnicas de gestão de estoque, alguns estudos foram realizados. Dentre eles, podem ser citados os de Mota e Cancio (2004), Wanke (2004, apud Freitas, Medeiros e Melo 2008), Vieira (2008), Carvalho (2009); Freitas e Vieira (2009); Santos, Teixeira e Carvalho (2009) e Santos e Varela (2010).

A pesquisa realizada por Wanke (2004, apud Freitas, Medeiros e Melo 2008), junto a 117 hospitais dos Estados da Geórgia, Alabama e Flórida dos Estados Unidos da América, objetivou identificar quais técnicas de gestão de estoques eram utilizadas nessas instituições. Os resultados apontaram que as três técnicas mais adotadas eram o Ponto de Pedido - PP (92,9\%), a Classificação ABC $(61,9 \%)$, e o Lote Econômico de Compras - LEC (54,8\%). 


\section{DETERMINANTES DO NÍVEL DOS ESTOQUES PÚBLICOS: MENSURAÇÃO NAS CAPITAIS DOS ESTADOS DA REGIÃO SUL DO BRASIL \\ Paulo Sérgio Almeida dos Santos - Odir Luiz Fank - Patrícia Siqueira Varela}

Mota e Cancio (2004), em seu estudo, avaliaram o nível dos estoques da administração pública federal. Os resultados comprovaram a existência de excesso de estoques, tais como os de materiais de consumo no setor público federal, em percentual médio superior a 80\%, no período correspondente aos anos de 1999 a 2003.

Vieira (2008) apontou aspectos inconclusos da agenda do Sistema Único de Saúde (SUS) para a qualificação dos serviços farmacêuticos no Brasil. Para isso, realizou 660 fiscalizações e analisou 659 relatórios. Em 62 municípios, os recursos da assistência farmacêutica não foram auditados, o que resultou em uma amostra final de 597 municípios. Desses, 90,3\% apresentaram problemas na gestão de recursos ou serviços. Em 71\% dos municípios, foi verificada a falta de controle de estoque ou controle deficitário e em 39\% dos municípios, apresentaram-se condições inadequadas de armazenamento. Verificou-se falta de medicamentos em $24 \%$ dos municípios.

Freitas e Viera (2009) identificaram por meio de um estudo comparativo planejado, a política de ressuprimento mais adequada à aquisição de medicamentos pela esfera pública estadual, bem como revelar o desempenho superior de sistemas inteligentes, quando aplicados a cenários de previsão de demanda e comparados a outras técnicas analogamente viáveis. Os autores constataram a superioridade de sistemas inteligentes em relação a técnicas de previsão de demanda tradicionais, bem como a inadequação das políticas de aquisição de medicamentos praticadas pelo Estado quando comparadas às alternativas dimensionadas no estudo realizado.

Carvalho (2009) verificou a gestão dos estoques de materiais nos almoxarifados da administração pública do Estado da Bahia. O responsável pelo almoxarifado desconhece a importância da gestão dos estoques e não utiliza nenhum método que dê suporte a uma gestão eficiente e eficaz, de maneira a contribuir com a redução dos gastos públicos e a otimização dos recursos na administração pública. Verificou-se a existência de 190 itens sem movimentação, representando um valor de $\mathrm{R} \$ 227.026,86 ; 622$ itens com quantidade acima do estoque máximo; 957 itens abaixo 
DETERMINANTES DO NÍVEL DOS ESTOQUES PÚBLICOS: MENSURAÇÃO NAS CAPITAIS DOS ESTADOS DA REGIÃO SUL DO BRASIL

Paulo Sérgio Almeida dos Santos - Odir Luiz Fank - Patrícia Siqueira Varela

do estoque mínimo e 961 itens em ponto de ressuprimento. Também foram encontradas discrepância entre o saldo físico e contábil, demonstrando total falta de controle.

Santos, Teixeira e Carvalho (2009) objetivaram avaliar o controle de estoques e identificar a potencialidade de redução deles em uma prefeitura da Região Norte do Paraná. Verificou-se a existência de excesso de estoques, como o de material de consumo, na prefeitura deste município, em percentual médio superior a $75,60 \%$, nos anos de 2003 a 2007, bem como, o demorado consumo de materiais pela entidade, o que acaba por acumular um volumoso estoque em seus almoxarifados.

Santos e Varela (2010) fizeram uma comparação das normas emitidas pelos órgãos reguladores brasileiros e internacionais, bem como verificaram se os estados com melhor desempenho quanto à gestão dos estoques podem ser diferenciados quanto ao grau de evidenciação de informações sobre os mesmos, entre outros fatores. Os achados do artigo no período analisado, o desempenho dos estados, dado pelo prazo médio de renovação de estoques, melhorou no ano eleitoral em quase todas as regiões e, em seguida, piorou novamente. O tempo, em média, que os estados brasileiros renovavam seus estoques em 2008 era de 180 dias, sendo o mínimo de 33 dias e o máximo 660 dias. Em relação aos fatores que poderiam estar associados ao bom desempenho, verificou-se que a adoção do Sistema de Registro de Preços e do Portal de Compras está relacionada positivamente com o desempenho e que o índice de transparência estadual e o grau de evidenciação contábil de informações sobre estoques não possuem interdependência com o desempenho.

\section{METODOLOGIA E LIMITAÇÕES}

Este estudo constitui-se de uma pesquisa descritiva, do tipo documental e levantamento, com abordagem quantitativa, dos dados. 


\section{DETERMINANTES DO NÍVEL DOS ESTOQUES PÚBLICOS: MENSURAÇÃO NAS CAPITAIS DOS ESTADOS DA REGIÃO SUL DO BRASIL \\ Paulo Sérgio Almeida dos Santos - Odir Luiz Fank - Patrícia Siqueira Varela}

Neste contexto, para alcançar o objetivo da pesquisa foram analisados os saldos das contas estoques (balanço patrimonial), material de consumo e material de distribuição gratuita (balanço orçamentário) referentes ao período de 2002 a 2008, totalizando sete anos analisados. Os dados foram obtidos junto à Secretaria do Tesouro Nacional - STN e são referentes àqueles disponíveis no site da referida instituição.

Os demonstrativos contábeis citados correspondem às três prefeituras das capitais dos Estados de Santa Catarina, Paraná e Rio Grande Sul. Justifica esta amostra, pelo fato da Região Sul ser a segunda região mais rica do país, logo atrás somente do Sudeste.

Para um determinado exercício, considerou-se como estoque inicial o estoque final do período anterior contido no balanço patrimonial das prefeituras. Para a mensuração das compras, foi considerado o somatório das contas de material de consumo e material de distribuição gratuita contidas no balanço orçamentário. De acordo com a Instrução Normativa no 205 (1988), o acompanhamento dos níveis de estoque e as decisões de quando e quanto comprar deverão ocorrer em função dos seguintes fatores de ressuprimento:

a) Consumo Médio Mensal (C) - média aritmética do consumo nos últimos

12 meses;

b) Tempo de Aquisição (T) - período entre a emissão do pedido de compra e o seu recebimento;

c) Intervalo de Aquisição (I) - período entre duas aquisições normais e sucessivas;

d) Estoque Mínimo ou de Segurança (Em) - menor quantidade de material mantido em estoque para atender um consumo superior ao estimado para certo período ou para a demanda normal; 


\section{DETERMINANTES DO NÍVEL DOS ESTOQUES PÚBLICOS: MENSURAÇÃO NAS CAPITAIS DOS ESTADOS DA REGIÃO SUL DO BRASIL}

Paulo Sérgio Almeida dos Santos - Odir Luiz Fank - Patrícia Siqueira Varela

e) Estoque Máximo (EM) - maior quantidade de material admissível em estoque, para o consumo em certo período;

f) Ponto de Pedido (Pp) - nível de estoque que, ao ser atingido, determina imediata emissão de um pedido de compra, visando a recompletar o estoque máximo;

g) Quantidade a Ressuprir (Q) - quantidade a adquirir para recompor o estoque máximo.

As fórmulas utilizadas para mensurar os determinantes dos níveis dos estoques das prefeituras foram às apresentadas no Quadro 1. Dessa forma, as seguintes fórmulas foram utilizadas para a análise e interpretação dos dados da pesquisa.

Quadro 1 - Fórmulas utilizadas na pesquisa

\begin{tabular}{|c|c|}
\hline Fórmulas/Determinantes & Descrição \\
\hline $\begin{array}{l}\text { Consumo anual (CA) } \\
\qquad \mathbf{C A}=\mathbf{E I}+\mathbf{C O}-\mathbf{E F}\end{array}$ & $\begin{array}{l}\text { Onde: } \\
\mathrm{EI}=\text { estoque inicial } \\
\mathrm{Co}=\text { compras } \\
\mathrm{EF}=\text { estoque final }\end{array}$ \\
\hline $\begin{array}{l}\text { Consumo médio mensal (C) } \\
\qquad \mathrm{C}=\mathrm{CA} \div \mathbf{1 2}\end{array}$ & $\begin{array}{l}\text { Onde: } \\
\mathrm{CA}=\text { consumo anual }\end{array}$ \\
\hline $\begin{array}{l}\text { Estoque mínimo (Em) } \\
\qquad E m=C \times f\end{array}$ & $\begin{array}{l}\text { Onde: } \\
C=\text { consumo médio mensal } \\
f=25 \% \text { conforme IN } 205 / 88\end{array}$ \\
\hline $\begin{array}{l}\text { Estoque Máximo (EM) } \\
\qquad \mathbf{E M}=\mathbf{E m}+\mathbf{C} \times \mathbf{I}\end{array}$ & $\begin{array}{l}\text { Onde: } \\
\text { Em = estoque mínimo } \\
C=\text { consumo médio mensal } \\
\mathrm{I}=6 \text { meses (semestralmente de acordo com a IN } \\
\text { n. } 205 / 88\end{array}$ \\
\hline $\begin{array}{l}\text { Ponto de Pedido (Pp) } \\
\qquad \mathbf{P p}=\mathbf{E m}+\mathbf{C} \times \mathbf{T}\end{array}$ & $\begin{array}{l}\text { Onde: } \\
\text { Em = estoque mínimo } \\
\mathrm{C}=\text { consumo } \\
\mathrm{T}=2 \text { meses (bimestral) de acordo com Mota e } \\
\text { Cancio (2004) esta variável pode ser obtida por } \\
\text { meio da arbitrariedade pessoal. }\end{array}$ \\
\hline $\begin{array}{l}\text { Quantidade de Ressuprimento (Q) } \\
\qquad \mathbf{Q}=\mathbf{C} \times \mathbf{I}\end{array}$ & $\begin{array}{l}\text { Onde: } \\
\mathrm{C}=\text { consumo médio mensal } \\
\mathrm{I}=6 \text { meses (semestralmente) }\end{array}$ \\
\hline Prazo Médio de Rotação de Estoque (PMRE) & Onde: \\
\hline
\end{tabular}




\begin{tabular}{|c|c|}
\hline PMRE $=\mathrm{EF} \div \mathrm{CA} \times 360$ & $\begin{array}{l}\mathrm{EF}=\text { estoque final } \\
\mathrm{CA}=\text { consumo anual }\end{array}$ \\
\hline $\begin{array}{l}\text { Análise Horizontal (AH \%) } \\
\qquad X 2 \div \text { X1 × } 100-100\end{array}$ & $\begin{array}{l}\text { Onde: } \\
\mathrm{X} 2=\text { período anterior } \\
\mathrm{X} 1=\text { período atual }\end{array}$ \\
\hline $\begin{array}{l}\text { Nível de Estoques em R\$ } \\
\qquad \mathbf{n}=\mathbf{E F}-\mathbf{P p}\end{array}$ & $\begin{array}{l}\text { Onde: } \\
E F=\text { estoque final } \\
\mathrm{Pp}=\text { ponto de pedido }\end{array}$ \\
\hline $\begin{array}{l}\text { Nível de Estoques em \% } \\
\qquad \mathbf{N}=\mathbf{n} \div \mathbf{E F}\end{array}$ & $\begin{array}{l}\text { Onde: } \\
\mathrm{n}=\text { nível de estoques em } \mathrm{R} \$ \\
\mathrm{EF}=\text { estoque final }\end{array}$ \\
\hline
\end{tabular}

Fonte: Adaptado da Instrução Normativa no 205/88.

No que tange às limitações deste estudo, podemos destacar inicialmente a amostra utilizada, que, no caso, são as três prefeituras das capitais da Região Sul do Brasil. Portanto, generalizações quanto aos achados para prefeituras maiores ou menores às investigadas não podem ser feitas. Depois destacamos o período tomado como base para a realização da análise. Do mesmo modo, generalizações para períodos anteriores e posteriores também não podem ser feitas. Por fim, destacamos as variáveis ou fatores utilizados para analisar o nível de estoques das prefeituras investigadas, visto que alguns dos determinantes sugeridos pela instrução normativa no 205/88 têm arbitrariedade pessoal.

\section{RESULTADOS}

A Tabela 1 apresenta os saldos de estoque inicial, compras, estoque final e consumo anual das prefeituras de Florianópolis, Curitiba e Porto Alegre, respectivamente. 


\section{DETERMINANTES DO NÍVEL DOS ESTOQUES PÚBLICOS: MENSURAÇÃO NAS CAPITAIS DOS ESTADOS DA REGIÃO SUL DO BRASIL}

Paulo Sérgio Almeida dos Santos - Odir Luiz Fank - Patrícia Siqueira Varela

Tabela 1 - Evidenciação das contas de estoque inicial, compras, estoque final e consumo anual das prefeituras de Florianópolis, Curitiba e Porto Alegre no período de 2002 a 2008

\begin{tabular}{|c|c|c|c|c|c|c|c|c|c|c|c|c|c|}
\hline & 2002 & 2003 & $\mathrm{AH} \%$ & 2004 & $\mathrm{AH} \%$ & 2005 & $\mathrm{AH} \%$ & 2006 & $\mathrm{AH} \%$ & 2007 & $\mathrm{AH} \%$ & 2008 & $\mathrm{AH} \%$ \\
\hline \multicolumn{14}{|l|}{ Estoque Inicial } \\
\hline orianopolis & 41.982 & - & (100) & 386.298 & . & 362.024 & (6) & 397.841 & 10 & - & $(100)$ & . & - \\
\hline Curritiba & - & 2.256 .990 & - & 3.442 .453 & 53 & - & $(100)$ & 273.682 & - & 154.460 & (44) & 241.675 & 56 \\
\hline Porto Alegr & 777.311 & 7.276 .585 & 836 & 9.252 .156 & 27 & 9.730 .001 & 5 & 10.366 .302 & 7 & 10.720 .784 & 3 & 11.204 .050 & - \\
\hline TOTAL & 819.293 & 9.533 .575 & 1.064 & 13.080 .907 & 37 & 10.092 .025 & (23) & $11,037.825$ & 9 & 10.875 .244 & (l) & 11.445 .725 & 5 \\
\hline \multicolumn{14}{|l|}{$\overline{C o m p r a s}$} \\
\hline orianópolis & 16.215 .317 & 22.799 .365 & 41 & 24.409 .843 & 7 & 68.112 .787 & 179 & 33.585 .977 & (51) & 35.381 .558 & 5 & 40.551 .866 & 15 \\
\hline uritiba & 197.167 .865 & 239.422 .058 & 21 & 233.331.233 & (3) & 261.741 .954 & 12 & 285.381 .907 & 9 & 294.200 .279 & 3 & 328.677 .827 & 12 \\
\hline tito & 504.560 & 56.458 .648 & (3) & 63.877 .208 & 13 & 68.112 .787 & 7 & 66.467 .565 & (2) & 68.005 .674 & 2 & 72.923 .375 & 7 \\
\hline TOTAL & 71.887 .742 & 318.680 .072 & 17 & 321.618 .284 & 1 & 397.967 .528 & 24 & 385.435 .449 & (3) & 397.587 .511 & 3 & 442.153 .068 & 11 \\
\hline \multicolumn{14}{|l|}{ Estoque Final } \\
\hline Mis & . & 386.298 & . & 362.024 & (6) & 397.841 & 10 & - & $(100)$ & . & - & 174.435 & - \\
\hline intit & 6.990 & 3.442 .453 & F & - & $(100)$ & 273.682 & - & 154.460 & (44) & 241.675 & 56 & 391.338 & 62 \\
\hline tto & 276.585 & 9.252 .156 & 27 & 9.730 .001 & 5 & 10.366 .302 & 7 & 10.720 .784 & 3 & 11.204 .050 & 5 & 13.644 .288 & 22 \\
\hline TOTAL & 9.533 .575 & 13.080 .907 & 37 & 10.092 .025 & (23) & $11,037.825$ & 9 & 10.875 .244 & (1) & 11.445 .725 & 5 & 14.210 .060 & 24 \\
\hline \multicolumn{14}{|l|}{ Consumo Anual } \\
\hline & 299 & 22.413 .068 & 38 & & 9 & 68.076 .970 & 179 & 33.983 .817 & $(50)$ & 35.381 .558 & 4 & 40.377 .431 & 14 \\
\hline triti & 194.910 .874 & 238.236 .596 & 22 & 236.773 .686 & (l) & 261.468 .272 & 10 & 285.501 .129 & 9 & 294.113 .065 & 3 & 328.528 .164 & 12 \\
\hline Porto Alegre & 52.005 .287 & 54.483 .077 & 5 & 63.399 .363 & 16 & 67.476 .486 & 6 & 66.113 .084 & (2) & 67.522 .407 & 2 & 70.483 .137 & 4 \\
\hline TOTAL & 263.173 .460 & 315.132 .740 & 20 & 324.607 .166 & 3 & 397.021 .727 & 22 & 385.598 .030 & (3) & $397,017,030$ & 3 & 439.388 .733 & 11 \\
\hline
\end{tabular}

Fonte: Elaborado pelos autores com dados da pesquisa.

Pela análise dos estoques iniciais das prefeituras, tomados em conjunto, observa-se um crescimento de $1.064 \%$ em 2003 , em relação a 2002, sendo expressivos os aumentos nos estoques de Curitiba e Porto Alegre. Em 2004, as prefeituras, em conjunto, iniciaram o período com estoques 37\% maiores do que em 2003. Em 2005, houve uma redução nos estoques iniciais em relação ao período anterior, o mesmo ocorrendo em 2007. Em 2006 e 2008, seguiu-se a tendência de crescimento, mas em percentuais menos expressivos. Vale notar que, em todos os anos da análise, a prefeitura de Porto Alegre aumentou os estoques iniciais em relação ao ano anterior.

As compras das prefeituras apresentaram uma variação regular no período. Destaca-se a prefeitura de Curitiba por apresentar valores expressivos quando comparados aos valores das demais prefeituras. A prefeitura de Florianópolis demonstra aumento de 179\% em 2005, em relação a 2004. Em 2006 as compras da prefeitura de Florianópolis reduziram 51\%, quando comparado com 2005. 
DETERMINANTES DO NÍVEL DOS ESTOQUES PÚBLICOS: MENSURAÇÃO NAS CAPITAIS DOS ESTADOS DA REGIÃO SUL DO BRASIL

Paulo Sérgio Almeida dos Santos - Odir Luiz Fank - Patrícia Siqueira Varela

Quanto à análise dos estoques finais das prefeituras, demonstra-se a regularidade nos estoques de Porto Alegre, os quais se mantiveram constantes no período analisado. Curitiba apresentou variações representativas, chegando a $53 \%$ em 2003 em relação a 2002, bem como atingindo o percentual de $56 \%$ de crescimento em 2007 ante 2006. Os estoques finais das prefeituras segundo dados da FINBRA, fecharam o período em $24 \%$ de crescimento em 2008, conforme a Tabela 1 . A prefeitura de Curitiba nos dois últimos anos analisados apresentou quase os mesmo percentuais de crescimento, em 2007 ante 2006 foi de 56\%, e 2008 ante 2007 obteve $62 \%$ de crescimento em seus estoques finais.

O consumo anual da prefeitura de Florianópolis evidenciou $179 \%$ de crescimento em 2005 diante de 2004, este crescimento foi reduzido em 2006 apresentando uma queda representativa de 50\%. Na formação de estoques, a prefeitura de Porto Alegre foi a que apresentou um maior nível no período analisado. Porém, quanto ao consumo no mesmo período apresentou o menor nível. A prefeitura de Florianópolis obteve $10 \%$, e Curitiba que apresentou $8 \%$ na formação total de estoques, quanto ao consumo total a prefeitura curitibana apresentou $73 \%$ da totalidade consumida durante o período.

As Tabelas 2, 3, 4, 5 e 6 demonstram os determinantes dos níveis de estoques das prefeituras das três capitais sulistas: consumo mensal de estoques, estoque mínimo ou de segurança, estoque máximo, ponto de pedido ou ponto de ressuprimento e quantidade de ressuprimento.

Tabela 2 - Consumos mensais das prefeituras de Florianópolis, Curitiba e Porto Alegre no período de 2002 a 2008

\begin{tabular}{|c|c|c|c|c|c|c|c|c|c|c|c|c|c|}
\hline Consumo Mensal & 2002 & 2003 & $\mathrm{AH} \%$ & 2004 & $\mathrm{AH} \%$ & 2005 & $\mathrm{AH} \%$ & 2006 & $\mathrm{AH} \%$ & 2007 & $\mathrm{AH} \%$ & 2008 & $\mathrm{AH} \%$ \\
\hline Florianópolis & 1.354 .775 & 1.867 .756 & 38 & 2.036 .176 & 9 & 5.673 .081 & 179 & 2.831 .985 & .50 & 2.948 .463 & 4 & 3.364 .786 & 14 \\
\hline Curitiba & 16.242 .573 & 19.853 .050 & 22 & 19.731 .140 & -1 & 21.789 .023 & 10 & 23.791 .761 & 9 & 24.509 .422 & 3 & 27.377 .347 & 12 \\
\hline Porto Alegre & 4.333 .774 & 4.540 .256 & 5 & 5.283 .280 & 16 & 5.623 .040 & 6 & 5.509 .424 & -2 & 5.626 .867 & 2 & 5.873 .595 & 4 \\
\hline Total & 21.931 .122 & 26.261 .062 & 20 & 27.050 .596 & 3 & 33.085 .144 & 22 & 32.133 .170 & -3 & 33.084 .752 & 3 & 36.615 .728 & 11 \\
\hline
\end{tabular}

Fonte: Elaborado pelos autores com dados da pesquisa. 


\section{DETERMINANTES DO NÍVEL DOS ESTOQUES PÚBLICOS: MENSURAÇÃO NAS CAPITAIS DOS ESTADOS DA REGIÃO SUL DO BRASIL}

Paulo Sérgio Almeida dos Santos - Odir Luiz Fank - Patrícia Siqueira Varela

Os consumos anuais apresentados na Tabela 2, indicam que a prefeitura de Curitiba, entre as demais prefeituras apresentou os maiores consumos mensais. No entanto, cabe colocar que a prefeitura de Florianópolis registrou $38 \%$ de crescimento de consumo mensal em 2003, em relação a 2002. Já em 2006, a entidade alavancou seus consumos mensais em 179\% diante de 2005.

Tabela 3 - Estoques mínimos das prefeituras de Florianópolis, Curitiba e Porto Alegre no período de 2002 a 2008

\begin{tabular}{l|c|c|c|c|c|c|c|c|c|c|c|c|c}
\hline Estoque Mínimo & 2002 & 2003 & AH\% & 2004 & AH\% & 2005 & AH\% & 2006 & AH\% & 2007 & AH\% & 2008 & AH\% \\
\hline Florianópolis & 338.694 & 466.939 & 38 & 509.044 & 9 & 1.418 .270 & 179 & 707.996 & -50 & 737.116 & 4 & 841.196 & 14 \\
\hline Curitiba & 4.060 .643 & 4.963 .262 & 22 & 4.932 .785 & -1 & 5.447 .256 & 10 & 5.947 .940 & 9 & 6.127 .356 & 3 & 6.844 .337 & 12 \\
\hline Porto Alegre & 1.083 .443 & 1.135 .064 & 5 & 1.320 .820 & 16 & 1.405 .760 & 6 & 1.377 .356 & -2 & 1.406 .717 & 2 & 1.468 .399 & 4 \\
\hline Total & $\mathbf{5 . 4 8 2 . 7 8 0}$ & $\mathbf{6 . 5 6 5 . 2 6 5}$ & 20 & $\mathbf{6 . 7 6 2 . 6 4 9}$ & 3 & 8.271 .286 & 22 & 8.033 .292 & -3 & 8.271 .189 & 3 & 9.153 .932 & 11 \\
\hline
\end{tabular}

Fonte: Elaborado pelos autores com dados da pesquisa.

Os mesmos pontos destacados na Tabela 2 são registrados na Tabela 3, visto que, os determinantes, quando calculados, dependem dos determinantes anteriores para serem mensurados, por tanto, acabam gerando uma cadeia de valores sucessivos em torno dos determinantes preliminares, logo, o percentual de acréscimo ou decréscimo de valores são iguais em todos os determinantes de cada uma das entidades analisadas.

Tabela 4 - Estoques máximos das prefeituras de Florianópolis, Curitiba e Porto Alegre no período de 2002 a 2008

\begin{tabular}{l|c|c|c|c|c|c|c|c|c|c|c|c|c}
\hline Estoque Máximo & 2002 & 2003 & $A H \%$ & 2004 & AH\% & 2005 & AH\% & 2006 & AH\% & 2007 & AH\% & 2008 & AH\% \\
\hline Florianópolis & 10.160 .812 & 14.008 .167 & 38 & 15.271 .323 & 9 & 42.548 .106 & 179 & 21.239 .886 & -50 & 22.113 .474 & 4 & 25.235 .894 & 14 \\
\hline Curitiba & 121.819 .296 & 148.897 .872 & 22 & 147.983 .554 & -1 & 163.417 .670 & 10 & 178.438 .206 & 9 & 183.820 .665 & 3 & 205.330 .103 & 12 \\
\hline Porto Alegre & 32.503 .304 & 34.051 .923 & 5 & 39.624 .602 & 16 & 42.172 .804 & 6 & 41.320 .677 & -2 & 42.201 .504 & 2 & 44.051 .961 & 4 \\
\hline Total & 164.483 .412 & 196.957 .962 & 20 & 202.879 .479 & 3 & 248.138 .580 & 22 & 240.998 .769 & -3 & 248.135 .643 & 3 & 274.617 .958 & 11 \\
\hline
\end{tabular}

Fonte: Elaborado pelos autores com dados da pesquisa. 
DETERMINANTES DO NÍVEL DOS ESTOQUES PÚBLICOS: MENSURAÇÃO NAS CAPITAIS DOS ESTADOS DA REGIÃO SUL DO BRASIL

Paulo Sérgio Almeida dos Santos - Odir Luiz Fank - Patrícia Siqueira Varela

Os estoques máximos apontam para os mesmos desempenhos dos determinantes anteriores, no que tange ao desempenho durante o período.

Tabela 5 - Pontos de pedidos das prefeituras de Florianópolis, Curitiba e Porto Alegre no período de 2002 a 2008

\begin{tabular}{l|c|c|c|c|c|c|c|c|c|c|c|c|c}
\hline Ponto de Pedido & 2002 & 2003 & AH\% & 2004 & AH\% & 2005 & AH\% & 2006 & AH\% & 2007 & AH\% & 2008 & AH\% \\
\hline Florianópolis & 3.386 .937 & 4.669 .389 & 38 & 5.090 .441 & 9 & 14.182 .702 & 179 & 7.079 .962 & .50 & 7.371 .158 & 4 & 8.411 .965 & 14 \\
\hline Curitiba & 40.606 .432 & 49.632 .624 & 22 & 49.327 .851 & .1 & 54.472 .557 & 10 & 59.479 .402 & 9 & 61.273 .555 & 3 & 68.4433 .368 & 12 \\
\hline Porto Alegre & 10.834 .435 & 11.350 .641 & 5 & 13.208 .201 & 16 & 14.057 .601 & 6 & 13.773 .559 & -2 & 14.067 .168 & 2 & 14.683 .987 & 4 \\
\hline Total & 54.827 .804 & $\mathbf{6 5 . 6 5 2 . 6 5 4}$ & 20 & 67.626 .493 & 3 & 82.712 .860 & 22 & 80.332 .923 & -3 & 82.711 .881 & 3 & 91.539 .320 & 11 \\
\hline
\end{tabular}

Fonte: Elaborado pelos autores com dados da pesquisa.

O ponto de pedido é um dos determinantes mais importantes para a gestão dos estoques (FREITAS; VIERA, 2009). Caso o nível dos estoques seja mensurado equivocadamente, pode-se haver um ressuprimento em maior ou em menor quantidade, ocorrendo sérios riscos de possíveis faltas de materiais para a sua prestação de serviço. Naquele caso poderá gerar para a entidade pública maiores custos além do custo de aquisição, por exemplo, custos de estocagem, seguros, manutenção, mão de obra etc., para o gerenciamento de seus estoques, bem como o desperdício de recursos públicos.

Na Tabela 5, por exemplo, os pontos de pedidos nas prefeituras, em 2008 apresentaram crescimento de $11 \%$ diante de 2007; em relação ao ano inicial, 2002, obteve-se uma queda de $9 \%$.

Tabela 6 - Ressuprimento das prefeituras de Florianópolis, Curitiba e Porto Alegre no período de 2002 a 2008

\begin{tabular}{l|c|c|c|c|c|c|c|c|c|c|c|c|c}
\hline Ressuprimento & \multicolumn{1}{|c|}{2002} & \multicolumn{1}{|c|}{2003} & AH\% & \multicolumn{1}{|c|}{2004} & AH\% & \multicolumn{1}{c}{2005} & AH\% & 2006 & AH\% & 2007 & AH\% & 2008 & AH\% \\
\hline Florianópolis & 8.128 .650 & 11.206 .534 & 38 & 12.217 .059 & 9 & 34.038 .485 & 179 & 16.991 .909 & -50 & 17.690 .779 & 4 & 20.188 .716 & 14 \\
\hline Curitiba & 97.455 .437 & 119.118 .298 & 22 & 118.386 .843 & -1 & 130.734 .136 & 10 & 142.750 .564 & 9 & 147.056 .532 & 3 & 164.264 .082 & 12 \\
\hline Porto Alegre & 26.002 .643 & 27.241 .538 & 5 & 31.699 .682 & 16 & 33.738 .243 & 6 & 33.056 .542 & -2 & 33.761 .204 & 2 & 35.241 .569 & 4 \\
\hline Total & 131.586 .730 & 157.566 .370 & 20 & 162.303 .584 & 3 & 198.510 .864 & 22 & 192.799 .015 & -3 & 198.508 .515 & 3 & 219.694 .367 & 11 \\
\hline
\end{tabular}

Fonte: Elaborado pelos autores com dados da pesquisa. 
DETERMINANTES DO NÍVEL DOS ESTOQUES PÚBLICOS: MENSURAÇÃO NAS CAPITAIS DOS ESTADOS DA REGIÃO SUL DO BRASIL

Paulo Sérgio Almeida dos Santos - Odir Luiz Fank - Patrícia Siqueira Varela

O determinante de ressuprimento, o último elemento, da cadeia dos determinantes, também apresentou os mesmos índices percentuais de variância, demonstrados nas tabelas anteriores. A Tabela 7 evidencia o nível de estoque em valores financeiros.

Tabela 7 - Nível de estoques das prefeituras de Florianópolis, Curitiba e Porto Alegre no período de 2002 a 2008

\begin{tabular}{|c|c|c|c|c|c|c|c|c|c|c|c|c|c|}
\hline Nivel de Estoques & 2002 & 2003 & AH\% & 2004 & $\mathrm{AH} \%$ & 2005 & $\mathrm{AH} \%$ & 2006 & $\mathrm{AH} \%$ & 2007 & $\mathrm{AH} \%$ & 2008 & AHH \\
\hline Florianópolis & $(3.386 .937)$ & $(4.283 .091)$ & 26 & $(4.728 .417)$ & 10 & $(13.784 .861)$ & 192 & 7.079 .962 & -49 & $(7.371 .158)$ & 4 & $(8.277 .530)$ & 12 \\
\hline Curitiba & $(38.349 .442)$ & $(46.190 .171)$ & 20 & $(49,327.851)$ & 7 & $(54.198 .874)$ & 10 & 59.324 .942 & 9 & $(61.031 .880)$ & 3 & $(668.052 .030)$ & 2 \\
\hline Porto Alegre & $(3.577 .850)$ & $(2,098.485)$ & -41 & $(3.478 .200)$ & 66 & $(3.691 .299)$ & 6 & 3.052 .776 & .17 & $(2.863 .118)$ & .6 & $(1.039 .699)$ & \\
\hline Total & $(45.294,229)$ & $(52.571 .747)$ & 16 & $(57,534,468)$ & 9 & $(71,675,034)$ & 25 & $69,457.680$ & .3 & $(71.266 .150)$ & 3 & $(77.329 .259)$ & \\
\hline
\end{tabular}

Fonte: Elaborado pelos autores com dados da pesquisa.

Os determinantes de níveis de estoques obtidos, conforme fórmula demonstrada no Quadro 1, apontam em valores financeiros a falta de materiais nos almoxarifados das entidades municipais no período pesquisado, neste, a maior evolução ocorreu em 2005, no qual apresentou $25 \%$ em relação a 2004 . Se comparado a 2008 em relação a 2002, houve uma evolução de 71\% no nível dos estoques das entidades, mais precisamente a possível falta de materiais evolui nesse percentual durante o período da análise. A Figura 1, a seguir, demonstra percentualmente os níveis dos estoques dos municípios durante os sete anos estudados.

Figura 1 - Nível dos estoques em \%

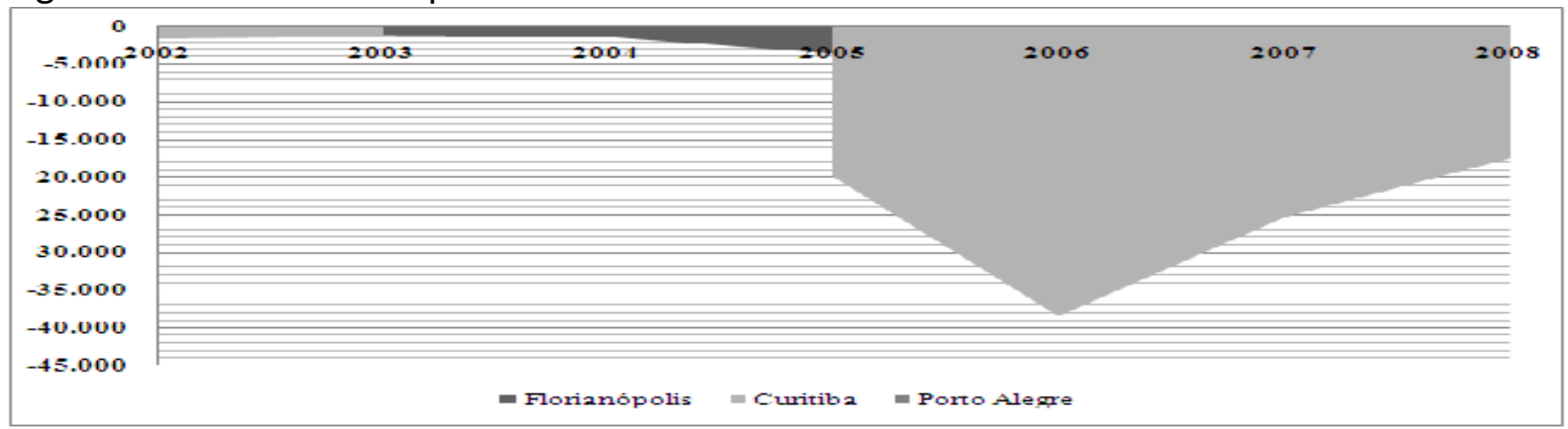

Fonte: Elaborado pelos autores com dados da pesquisa. 


\section{DETERMINANTES DO NÍVEL DOS ESTOQUES PÚBLICOS: MENSURAÇÃO NAS CAPITAIS DOS ESTADOS DA REGIÃO SUL DO BRASIL}

Paulo Sérgio Almeida dos Santos - Odir Luiz Fank - Patrícia Siqueira Varela

Grande parte das entidades avaliadas demonstrou percentual abaixo do nível zero, este considerado como bom, segundo a filosofia do just in time, no entanto, os níveis em valores apresentados poderiam indicar a necessidade de materiais nas entidades. A prefeitura de Curitiba foi a que, mais demonstrou percentuais distantes do nível zero, porém a prefeitura porto-alegrense demonstrou por meio da Figura 1, manter um nível de estoque necessário para suas atividades.

A Figura 2 indica a quantidade de dias em que os estoques das prefeituras sulistas giraram, ou seja, quantos dias, em média, os itens permaneceram em estoques.

Figura 2 - Prazo médio de rotação dos estoques (PMRE)

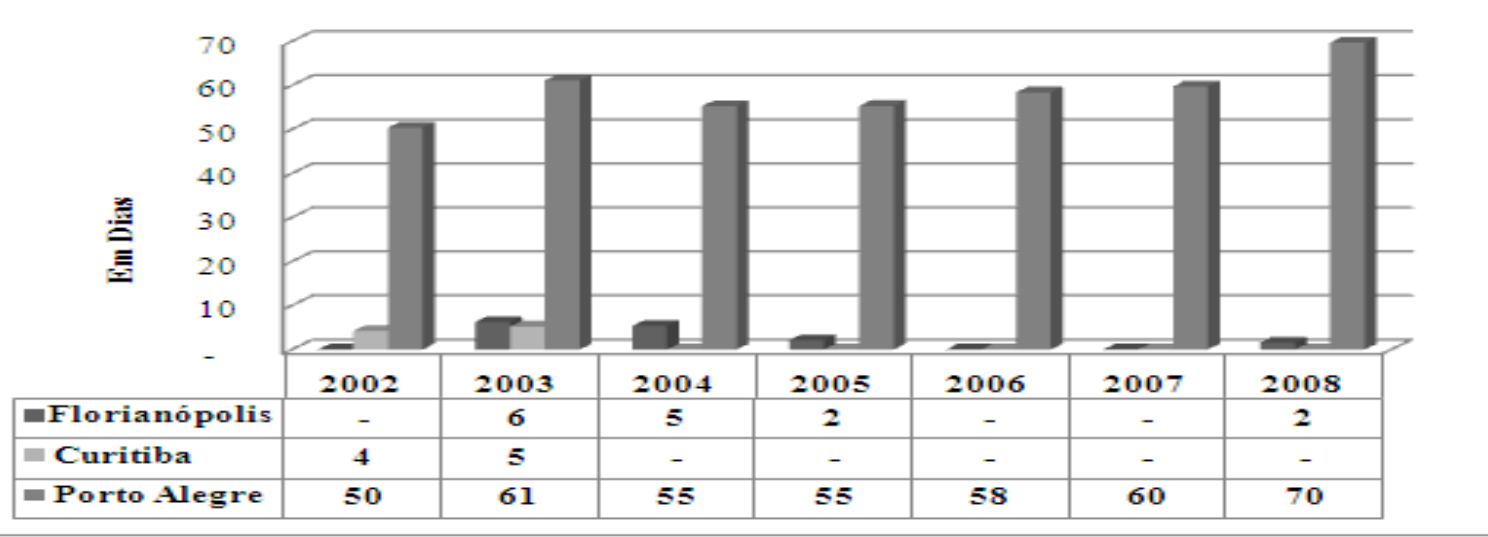

Fonte: Elaborado pelos autores com dados da pesquisa.

Pela análise dos prazos médios, é possível perceber que Florianópolis e Curitiba renovam seus estoques em um prazo muito curto de tempo. Uma possível explicação para esse fato seria a utilização de instrumentos de gestão mais flexíveis quanto à realização de compras, como o Sistema de Registro de Preços. Por outro lado, os resultados podem reforçar as análises dos níveis de estoques, ou seja, que existe o problema de falta de estoques. Por sua vez, Porto Alegre apresenta prazos médios bem superiores, mas ao mesmo tempo níveis de estoques mais adequados.

Prazo de renovação de estoques igual a zero, inicialmente, poderia indicar que a prefeitura trabalha dentro da filosófica just in time, todavia na análise devem ser 
DETERMINANTES DO NÍVEL DOS ESTOQUES PÚBLICOS: MENSURAÇÃO NAS CAPITAIS DOS ESTADOS DA REGIÃO SUL DO BRASIL

Paulo Sérgio Almeida dos Santos - Odir Luiz Fank - Patrícia Siqueira Varela

consideradas as especificidades da atividade de compras no setor público. Pode-se buscar reduzir ao máximo a permanência dos materiais em estoque, mas dificilmente o prazo será próximo de zero, haja vista as exigências do processo de licitação.

\section{CONSIDERAÇÕES FINAIS}

Diante da grande repercussão a respeito dos estoques públicos, este estudo investigou a seguinte questão problema: "Qual o comportamento dos estoques, bem como a evolução dos mesmos, nas prefeituras das capitais dos estados da Região Sul do Brasil?"

O objetivo central do estudo foi identificar os níveis de estoques das prefeituras das capitais dos estados da Região Sul do Brasil, bem como os seus determinantes e evolução ao longo do tempo.

A pesquisa foi realizada com base nas equações matemáticas definidas pela Instrução Normativa no 205 de 8 de abril de 1988, da ex-Secretaria de Administração da Presidência da República - SEDAP/PR, que tem como finalidade racionalizar, com a minimização de custos, o uso de material no âmbito da administração pública federal. Diante disso, o estudo quanto aos objetivos foi descritivo, no que tange ao procedimento documental e no que diz respeito à abordagem do problema quantitativo.

Após a aplicação das fórmulas intuídas pela Instrução Normativa no 205/88, bem como do prazo médio de rotação de estoque - PMRE, os resultados conforme o modelo da citada norma, indicou que durante o período analisado de 2002 a 2008 houve a falta de estoques nos almoxarifados das entidades pesquisadas. Os resultados encontrados no trabalho indicam que os controles de estoques das entidades investigadas não se mantiveram uniformes. Esse desequilíbrio também foi constatado em outras pesquisas sobre o assunto. Percebeu-se que no período estudado os níveis de estoques relativos a estoque inicial, estoque final, compras, 
DETERMINANTES DO NÍVEL DOS ESTOQUES PÚBLICOS: MENSURAÇÃO NAS CAPITAIS DOS ESTADOS DA REGIÃO SUL DO BRASIL

Paulo Sérgio Almeida dos Santos - Odir Luiz Fank - Patrícia Siqueira Varela

consumo, estoque mínimo, estoque máximo, ponto de pedido e quantidade de ressuprimento das prefeituras tanto evoluíram, como decresceram. O decréscimo indicou a falta de materiais de consumo e de distribuição gratuita nos almoxarifados dos municípios, a qual foi constatada em valores financeiros que evoluíram em $71 \%$, entre o período de 2002 a 2008, bem como pelo prazo médio de renovação dos estoques que, em alguns casos, percebeu-se que as capitais não tinham estoque final de materiais para se fazer o cálculo da renovação dos estoques.

Adicionalmente, este estudo fornece evidências sobre o caos que ainda há nos estoques públicos brasileiros, corroborando estudos anteriores feitos sobre o assunto e indicando que os controles internos das entidades públicas necessitam de um gerenciamento de estoques mais efetivo com o intuito de otimizar a alocação dos recursos públicos. Talvez a desburocratização do processo de compras pelo poder público (FERNANDES, 2010) possa auxiliar na reposição e, consequentemente o controle dos estoques públicos, ou até mesmo, a adoção de sistemas de gestão inteligentes como sugerido por Freitas e Vieira (2009).

Portanto, as saídas de suprimentos aos diversos setores da administração municipal são registradas antecipadamente a entradas de suprimentos no almoxarifado no qual os materiais já estão devidamente alocados nesse. Contudo, a visão de planejamento e estratégia na administração dos estoques públicos faz-se necessário, tendo em vista que grandes são os custos em tornos dos estoques, os quais por sua vez poderão maximizar o valor do serviço público, afetando desse modo o oferecimento dos bens e serviços à população da região.

Estudos futuros poderão aumentar a gama de pesquisas relacionadas ao assunto, visto que ainda são comuns os estudos no setor público, principalmente àqueles que abordam estoques. O ideal seria trabalhar com os relatórios obtidos a partir dos relatórios contábeis nas webs site das próprias prefeituras. Não obstante, deve-se levar em consideração as limitações apresentadas pelo estudo para que não 
DETERMINANTES DO NÍVEL DOS ESTOQUES PÚBLICOS: MENSURAÇÃO NAS CAPITAIS DOS ESTADOS DA REGIÃO SUL DO BRASIL

Paulo Sérgio Almeida dos Santos - Odir Luiz Fank - Patrícia Siqueira Varela

seja feita a generalização dos resultados encontrados para outras entidades municipais brasileiras.

\section{DETERMINING THE LEVEL OF PUBLIC STOCKS: MEASUREMENT IN THE CAPITAL OF THE MEMBER OF THE SOUTHERN REGION OF BRAZIL}

\section{ABSTRACT}

One of the main targets of both private and public entities is to keep their inventories balanced, aiming to economy of resources. Therefore, this study investigated the following problem: What is the behavior of stocks and their evolution in the halls of the capitals of the southern states of Brazil? To this end the purpose of this study was to evaluate the inventory levels of municipal capitals of the states of southern Brazil and its determinants and evolution over time. Consequently, research regarding the goals was descriptive of the aims was descriptive in regard to documentation and procedure in respect of the quantitative approach to the problem. After application is made of mathematical formulas outlined in Instruction № 205/88. The results indicate that there were problems relating to lack of inventory in the warehouses of the town halls. This problem can possibly be generated around the output of goods in view of the issues of organizational purpose halls. Therefore, the outputs of supplies to various sectors of municipal administration are recorded in advance for input supplies in the warehouse where the materials are properly allocated to this. However, the view of planning and strategy in the administration of public inventories is necessary in order that the costs are large lathes in inventories, which in turn will maximize the value of public service, thereby affecting the offering of goods and services to the region's population. 
DETERMINANTES DO NÍVEL DOS ESTOQUES PÚBLICOS: MENSURAÇÃO NAS CAPITAIS DOS ESTADOS DA REGIÃO SUL DO BRASIL

Paulo Sérgio Almeida dos Santos - Odir Luiz Fank - Patrícia Siqueira Varela

Keywords: Inventories public. Buying public. Inventory control. Prefectures. Southern Brazil.

\section{REFERÊNCIAS}

ASSAF NETO, A.; SILVA, C. A. T. Administração do capital de giro. 3. ed. São Paulo: Atlas, 2007.

BRAGA, R. Fundamentos e Técnicas de Administração Financeira. São Paulo: Atlas, 1995.

BRASIL. Instrução Normativa n.o 205, de 08 de abril de 1988. Brasília, 1988. Disponível em: http://www.comprasnet.gov.br/.> Acesso em: 28 abr. 2010.

CARVALHO, C. S. V. A gestão dos estoques de materiais na administração pública. Dissertação, 2009. 79 fl. (Mestrado em Administração Estratégica). Universidade de Salvador. Salvador, 2009.

CHING, H.Y. Gestão de estoques na cadeia logística integrada. Atlas: São Paulo, 1999.

COSTA, J. C.; GONÇALVES, M. B.; GIACOBO, F. Gestão de estoques de materiais de baixíssimo giro considerando processos críticos para organização. In: SEMEAD, 8, 2005, São Paulo/SP, Anais... São Paulo: USP, 2005. CD-ROM.

DIAS, M. A. P. Administração de materiais. São Paulo: Atlas, 1995.

FERNANDES, C. C. C.. Transformações na Gestão de Compras da Administração

Pública Brasileira. In: Congreso Internacional Del Clad Sobre La Reforma Del Estado Y De La Administración Pública, 8, 2003, Panamá. Disponível em: < http://unpan1.un.org/intradoc/groups/public/documents/clad/clad0047330.pdf>. Acesso em: 28 abr. 2010.

FERNANDES, C. C. C. Política de compras e contratações: trajetória e mudanças na administração pública federal brasileira. 2010, 285 f. Tese (Doutorado em Administração Pública) - Fundação Getulio Vargas: São Paulo, 2010. 
DETERMINANTES DO NÍVEL DOS ESTOQUES PÚBLICOS: MENSURAÇÃO NAS CAPITAIS DOS ESTADOS DA REGIÃO SUL DO BRASIL

Paulo Sérgio Almeida dos Santos - Odir Luiz Fank - Patrícia Siqueira Varela

FREITAS, F. F. T.; MEDEIROS, C. V. S.; MELO, A. C. S. Aplicação de técnicas de gestão de estoques, como auxílio à tomada de decisões em compras públicas estaduais de medicamentos. In: ENCONTRO NACIONAL DE ENGENHARIA DE PRODUÇÃO, 23., 2008, Rio de Janeiro/RJ, Anais..., Rio de Janeiro: ABEPRO, 2008. CD-ROM.

FREITAS, F. F. T.; VIEIRA, G. E. M. Aplicação de sistemas inteligentes na reposição de estoques de medicamentos no setor público estadual. Revista de Inovação, Gestão e Produção - INGEPRO, v. 1, n.4, p. 1-12, 2009.

IUDÍCIBUS, S.; MARTINS, E.; GELBCKE, E. R. Manual de contabilidade das sociedades por ações: aplicável às demais sociedades. 6. ed. São Paulo: Atlas, 2003.

MORESI, E. A. D. Delineando o valor do sistema de informação de uma organização. Ci.Inf. Brasília, v. 29 n. 1, p. 14-24, jan./abr., 2000.

MOTA, F. G. L.; CANCIO, A. J. Avaliação da potencialidade de redução de estoques no governo federal. In: ENANPAD, 28., 2004, Curitiba/PR, Anais... Rio de Janeiro: ANPAD, 2004. CD-ROM.

QUELHAS, O. L.G.; MESQUITA, M. A.; LUSTOSA, L. J.; OLIVEIRA, R. J. Planejamento e controle da produção. Rio de Janeiro: Campus, 2008.

SALDANHA, C. Introdução á gestão pública. São Paulo: Saraiva, 2006.

SANTOS, P. S. A.; TEIXEIRA, E. C. B.; CARVALHO, M. J. Controle e minimização dos estoques da Prefeitura de Londrina (PR): uma proposta de otimização de recursos públicos. In: CONGRESSO UFSC CONTROLADORIA E FINANÇAS E INICIAÇÃO CIENTÍFICA EM CONTABILIDADE, 3., 2009, Florianópolis/SC. Anais... Florianópolis: UFSC, 2009. CDROM.

SANTOS, P. S. A.; VARELA, P. S. Desempenho da gestão dos estoques públicos e evidenciação: um estudo das demonstrações contábeis dos estados brasileiros. In: Encontro de Administração Pública e Governança da ANPAD, 4, 2010, Vitória/ES. Anais... Rio de Janeiro: ANPAD, 2010. CD-ROM.

SECRETARIA DO TESOURO NACIONAL: Finanças do Brasil (FINBRA), Dados Contábeis dos municípios brasileiros: 2003, 2004, 2005, 2006 E 2007. Disponível em: http://www.tesouro.fazenda.gov.br/.> Acesso em: 28 abr. 2009.

TORMEM, D. S.; METZNE, C. M.; BRAUN, L. M. S. Pregão Eletrônico como ferramenta de redução dos custos: um estudo de caso na prefeitura de Capitão Leônidas Marques 
DETERMINANTES DO NÍVEL DOS ESTOQUES PÚBLICOS: MENSURAÇÃO NAS CAPITAIS DOS ESTADOS DA REGIÃO SUL DO BRASIL

Paulo Sérgio Almeida dos Santos - Odir Luiz Fank - Patrícia Siqueira Varela

- PR CONGRESSO BRASILEIRO DE CUSTOS, 14, 2007, João Pessoa/PB. Anais... São Leopoldo, ABC, 2007. CD-ROM.

VIEIRA, F. S. Qualificação dos serviços farmacêuticos no Brasil: aspectos inconclusos da agenda do Sistema Único de Saúde. Rev Panam Salud Publica, Washington, v. 24, n. 2, p. 91-100, 2008. 